\title{
SER PROFESSOR DE FÍSICA: REPRESENTAÇÕES SOCIAIS NA LICENCIATURA
}

\author{
ADRIANO JOSÉ ORTIZ '* \\ https://orcid.org/0000-0002-2222-2603 \\ CARLOS ALBERTO DE OLIVEIRA MAGALHÃES JÚNIOR" ** \\ https://orcid.org/0000-0002-1116-0777
}

RESUMO: Neste trabalho, investigamos as representações sociais de ingressantes e de concluintes de licenciatura em Física de duas instituições públicas do estado do Paraná sobre "ser professor de Física". Os dados foram coletados com 54 licenciandos, por meio da técnica de evocação livre de palavras, que, na sequência, foram organizadas em grupos semânticos. Esses dados foram utilizados para a construção de quadros de quatro casas que possibilitaram identificar núcleo central e periferia das representações sociais. Entre os alunos dos primeiros anos, os elementos do núcleo se concentraram em uma perspectiva tradicionalista e positivista de ensino, apesar de haver a preocupação em desenvolver uma prática reflexiva. Tal resultado também permaneceu nos grupos de concluintes, indicando que a formação inicial não influenciou, de forma significativa, suas representações, que se aproximam mais ao senso comum do que aos conhecimentos científicos referentes à profissão docente. Palavras-chave: Formação de professores; Senso comum; licenciandos.

\section{SER PROFESOR DE FÍSICA: REPRESENTACIONES SOCIALES EN LA LICENCIATURA}

RESUMEN: En este trabajo, investigamos las representaciones sociales de estudiantes ingresantes y de estudiantes que estaban concluyendo la licenciatura en Física en dos instituciones públicas del estado de Paraná acerca de "ser profesor de Física". Los datos fueron recopilados con 54 estudiantes de licenciatura, por medio de la técnica

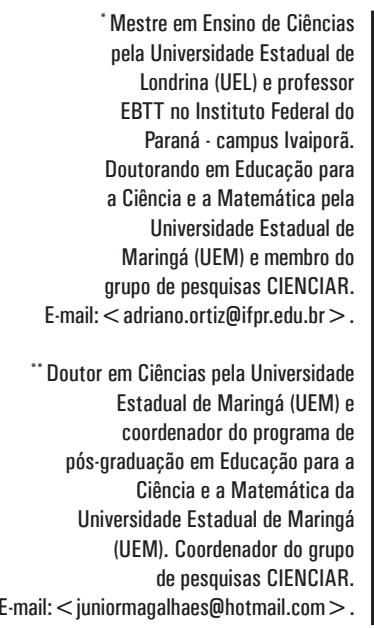

Mestre em Ensino de Ciências la Universidade Estadual de Londrina (UEL) e professor BTT no Instituto Federal do Paraná - campus Ivaiporã. Doutorando em Educação para Universidade Estadual de Maringá (UEM) e membro do grupo de pesquisas CIENCIAR. E-mail: $<$ adriano.ortiz@ifpredubr $>$. Estadual de Maringá (UEM) e coordenador do programa de Ciêncián versidade Estadual de Maringá EM). Coordenador do grupo E-mail:<juniormagalhaes@hotmail.com>

\footnotetext{
I Instituto Federal do Paraná, Ivaiporã, PR - Brasil.

" Universidade Estadual de Maringá, Programa de Pós-graduação em Educação para a Ciência e a Matemática, Maringá, PR - Brasil.
} 
de evocación libre de palabras, las cuales, enseguida, fueron organizadas en grupos semánticos. Esos datos se utilizaron con objeto de construir recuadros de cuatro casas que posibilitaron identificar el núcleo central y la periferia de las representaciones sociales. Entre los alumnos de los primeros años, los elementos del núcleo se concentraron en una perspectiva tradicionalista y positivista de la enseñanza, aunque hubiese la preocupación por desarrollar una práctica reflexiva. Ese resultado también se manifestó en los grupos de los que estaban concluyendo, lo que indica que la formación inicial no influyó, de manera significativa, en sus representaciones, las cuales se aproximan más al sentido común que a los conocimientos científicos referentes a la profesión docente.

Palabras clave: Formación de profesores; Sentido común; Estudiantes de licenciatura.

\section{TO BE PHYSICS TEACHER: SOCIAL REPRESENTATION IN LICENTIATE DEGREE}

ABSTRACT: In this study we investigated the Social Representations (SR) about "being a Physics teacher" of freshman and graduating students of two public institutions in Paraná state. The data was collected among 54 graduates using free evocation of words and processes organized in semantic groups to build frames for four houses to make possible to identify the central nucleus and periphery of SR. In the freshman groups investigated the core elements focused on a tradicionalist and positivist teaching perspective despite the concern to develop a reflexive practice. That result remained among the graduating group indicating that inicial training did not significantly influenced their representations wich are closer to common sense than scientific knowledge concerning the teaching profession.

Keywords: Teacher training; Common sense; Physics students. 


\section{INTRODUÇÃO}

No Brasil, a área de pesquisa em Ensino de Física tem se desenvolvido, ao menos, desde a década de 1960, com a implantação do projeto Physical Science Study Committee (PSSC). Evidentemente não ignoramos a existência de discussões anteriores a essa data voltadas ao ensino desse componente curricular, entretanto não percebemos um empenho que tenha resultado no desenvolvimento de colaborações científicas significativas nessa área (ALMEIDA JÚNIOR, 1979; ROSA C.; ROSA A., 2012).

A partir da década de 1960, mais especificamente no início dos anos de 1970, no Brasil, a educação para o mercado de trabalho foi o foco governamental. Nesse período, foram criados os primeiros cursos de pós-graduação stricto sensu em Ensino de Física, cujas instituições pioneiras foram a Universidade de São Paulo (USP) e a Universidade Federal do Rio Grande do Sul (UFRGS).

Nesse contexto, de acordo com Rosa C. e Rosa A. (2012), o campo de pesquisa em Ensino de Física foi fortalecendo-se e proporcionando discussões de temas que incluem metodologias de ensino, avaliação, interdisciplinaridade e relação entre ciência, tecnologia e sociedade.

Embora muitas pesquisas tenham sido realizadas nessa área nos últimos 50 anos, grande parte do conhecimento produzido continua não chegando às salas de aula. Ainda hoje, mesmo entre os incontáveis resultados e os inúmeros documentos oficiais, observa-se o predomínio de um ensino de Física sustentado na racionalidade técnica, mais preocupado em treinar alunos para avaliações destinadas ao ingresso no ensino superior do que, de fato, em estimular a reflexão crítica, a qual evidencia o papel dessa ciência em um contexto histórico e social (MONTEIRO, 2010; ROSA C.; ROSA A., 2012).

Tal problema passa pela formação de professores, cujas experiências e vivências participam da construção das noções prévias e das representações sociais que afetam sua prática (ORTIZ; MAGALHÃES JÚNIOR, 2017). Nesse sentido, não bastam alterações curriculares e o desenvolvimento de materiais e de metodologias inovadoras, se for ignorada a preparação do profissional docente a quem caberá apresentar tais propostas aos alunos.

Não podemos deixar de destacar que as condições de trabalho enfrentadas pelos professores não estão dissociadas da sua formação. Para Saviani (2009), as condições precárias de trabalho tanto neutralizam a ação dos professores como se apresentam como fator de desestímulo à procura e à dedicação a cursos de formação docente. O trabalho de Lunkes e Rocha Filho (2011) reforça essa leitura, ao identificar uma rejeição pela carreira docente, que parece envolver o status social dessa profissão.

Por isso, é relevante compreendermos possíveis relações entre a licenciatura e as representações sociais de alunos dessa área sobre ser professor de Física. Esperamos que, ao longo do curso, os licenciandos se aproximem do conhecimento científico referente à atuação docente. Isso, porém, tem ocorrido?

Com o intuito de contribuir para essa reflexão, propomo-nos a investigar quais representações sobre ser professor de Física são apresentadas por licenciandos de duas instituições públicas localizadas no estado do Paraná os quais estão iniciando ou concluindo o curso de licenciatura em Física. 


\section{SER PROFESSOR: ENTRE O UNIVERSO REIFICADO E O UNIVERSO CONSENSUAL}

A diferença entre o universo reificado e o universo consensual é que o primeiro representa o conhecimento construído mediante regras objetivas, apresentando rigor lógico, teórico e metodológico. A participação do sujeito nesse universo é dada de acordo com sua qualificação ou seu mérito. Já o universo consensual é construído por meio da conversação. Ele é composto por grupos de pessoas que podem falar por qualquer um de seus membros. Nesse universo a memória se sobrepõe à dedução e a imagem à realidade (MOSCOVICI, 2015).

Com base nesses conceitos, podemos compreender a existência de conhecimentos científicos oriundos do universo reificado, bem como conhecimentos de senso comum que surgem no universo consensual.

A formação inicial de professores implica um ambiente de construção do conhecimento reificado. Para tanto, os conhecimentos teóricos precisam estar relacionados à prática ao longo de toda a formação, de forma a estimular, entre os educadores, a autonomia racional que lhes possa possibilitar o desenvolvimento da compreensão de mundo e de suas práticas pedagógicas (SALAZAR, 2005; MONTEIRO; NARDI; BASTOS FILHO, 2009).

Não basta ao professor uma perspectiva positivista e tradicional na qual o importante é dominar o conteúdo e conhecer táticas para expô-lo de forma linear como verdades a serem armazenadas que, posteriormente, devem ser apresentadas em um teste. Em outras palavras, ser professor não se trata de dominar o conteúdo e possuir bom senso ou ter o dom para ensinar (GATTI; BARRETO, 2009; ORTIZ; MAGALHÃES JÚNIOR, 2017).

No contexto de formação de professores, temos o Pedagogical Knowledge Content (PCK) que se estrutura na relação entre os conhecimentos, os conteúdos, os aspectos pedagógicos, o contexto e os alunos (SHULMAN, 1986; 1987; SALAZAR, 2005). O PCK envolve saberes científicos e saberes pedagógicos que possibilitam ao professor compreender como diferentes temas, problemas e questões são organizados, representados e adaptados aos interesses e às capacidades dos alunos, de forma que o saber que o professor domina se torne compreensível aos demais membros do grupo em que atua (SHULMAN, 1986; 1987).

Conhecer o conteúdo significa dominar os conceitos básicos de uma área de conhecimento, incluindo sua epistemologia, suas correlações e aproximação com outros temas e áreas (SHULMAN, 1986; 1987). Apenas dominar esse conhecimento não é suficiente para a formação de um professor crítico, pois para este não basta transmitir as informações já desenvolvidas pela humanidade; faz-se necessário ser um articulador crítico e mediador no processo pedagógico (BEHRENS, 2013).

O docente deve compreender o aluno como sujeito histórico-social, que traz consigo conhecimentos e experiências prévias. Em sua ação pedagógica, o professor também desenvolve elementos de afetividade que impactam suas escolhas metodológicas, que atuam diretamente na sua relação com o aluno e influenciam a aprendizagem do aluno e a relação deste com o conteúdo (SALAZAR, 2005; TASSONI; LEITE, 2013).

Compreender o contexto é outro aspecto que faz parte do trabalho docente. É importante que os cursos de licenciatura formem professores capazes de tomar decisões e fazer ponderações de acordo com a situação na qual estão atuando. 
Nesse sentido, as características, a cultura e a organização da comunidade, as políticas e as formas de financiamento relacionadas à conjuntura são fundamentais para desenvolver a consciência de que ações de diferentes configurações são imprescindíveis em diferentes situações de ensino e de aprendizagem (SHULMAN, 1987; TASSONI; LEITE, 2013).

Os conhecimentos pedagógicos dizem respeito à habilidade de organizar, selecionar, distribuir e dosar os conhecimentos relevantes para a formação dos alunos (SAVIANI, 2009). Além de serem fundamentais, é importante que tais conhecimentos não se restrinjam à teoria e que seu ensino não se limite a momentos específicos, mas que estejam, ao longo de toda a formação, vinculados à prática docente.

Apesar de esses conhecimentos científicos participarem ativamente da profissão docente, muitas vezes, eles são suplantados por representações sociais que são elementos conceituais que surgem do universo consensual, orientam ações docentes e agem como instrumento de leitura da realidade, portanto influenciam os comportamentos docentes, bem como as suas perspectivas e suas decisões (MOSCOVICI, 2015).

As representações sociais têm uma função convencional e prescritiva que promove a comunicação e norteia condutas, de modo a facilitar a construção de uma identidade grupal, apresentando-se como teorias do senso comum (MOSCOVICI, 2015). Elas são definidas como convencionais porque dão forma, categorizam e organizam os elementos em modelos que passam a sintetizá-los. Já o papel prescritivo dessas representações relaciona-se à sua imposição sobre os sujeitos, de forma que as ideias passadas permanecem ativas, mudando e se infiltrando nas suas ideias atuais (ALVES-MAZZOTTI, 2008; MOSCOVICI, 2015).

Uma característica das representações sociais que não pode ser ignorada é a dificuldade de alteração. Elas se organizam em torno de um núcleo central, composto por elementos mais estáveis que possuem a função generadora que cria e transforma significados, de tal sorte que dão sentido e valor às representações e a função organizadora que estrutura os elos entre os elementos de uma representação social, tornando-a estável (ABRIC, 2000).

Devido a essas características, o núcleo central assegura a continuidade das representações sociais em contextos móveis e em evolutivos, sendo resistente à mudança. Isso implica que a transformação de uma representação social pressupõe que seu núcleo central tenha sofrido alterações (ABRIC, 2000). É essa compreensão que permite o estudo comparativo entre as representações sociais e a diferenciação entre grupos sociais.

Esse núcleo é protegido por uma periferia que apresenta elementos mais acessíveis, algumas vezes contraditórios, desde que mantenham o núcleo central estável (ABRIC, 2000). Os elementos periféricos têm as seguintes funções: concretização (interface entre o núcleo central e a realidade concreta, tornando a representação social compreensível e transmissível); regulação (adaptação das representações sociais ao contexto, integrando e adaptando informações novas para que não entrem em conflito com o núcleo central); defesa (capacidade de absorver a maior parte das transformações de uma representação, ponderando, interpretando ou deformando informações, de forma a integrar elementos à representação social, mesmo que eles sejam contraditórios) (ABRIC, 2000). 
No que se refere às possíveis mudanças em uma representação social, Abric (2000) caracteriza três tipos de alterações: a resistente, cujas mudanças são geridas pelo sistema periférico; a progressiva, na qual ocorre uma transformação sem ruptura, pois os novos conceitos não são totalmente contraditórios em relação ao núcleo central; a brutal, que se caracteriza pelo fato de os conceitos serem totalmente contraditórios e causarem uma transformação direta de toda a representação.

É importante compreendermos que, para Abric (2000), essas mudanças ocorrem quando o sujeito se depara com uma situação contraditória considerada irreversível. Caso contrário, elas ficarão restritas à periferia, sem que o núcleo central seja alterado. Essas características fazem com que as representações sociais possam tornar-se um obstáculo ao processo de aprendizagem, atuando como uma barreira à compreensão de um conceito científico.

Os impactos das representações na formação de professores são observados em diversas pesquisas que apontam os seguintes resultados: (a) a formação não possibilitou aos docentes a familiaridade com os conteúdos a serem ensinados, tampouco lhes preparou para lidar com as dificuldades dos alunos (MAGALHÃES; MAIA; ALVES-MAZZOT'TI, 2010); (b) há núcleos de representação diferentes para licenciandos do gênero feminino (atuação profissional - características e comportamentos esperados de um professor) e do gênero masculino (conteudistas - capacidade de aprender o conteúdo e de motivação pessoal) (ORTIZ; MAGALHÃES JÚNIOR, 2017). Nesse contexto, as representações sociais apresentadas por licenciandos não podem ser ignoradas, dada sua influência no processo de aprendizagem, bem como na sua atuação profissional como docente.

A discussão não pode se restringir à divisão entre aqueles que 'dominam o conteúdo, mas não possuem didática' e os que 'possuem uma boa didática, porém não conhecem o conteúdo' ou ainda entre aqueles que 'não possuem vocação docente'.

Uma perspectiva dessa natureza reforça estereótipos e representações a respeito da profissão docente que fortalecem uma expectativa positivista de que ser professor significa apenas ter bom domínio do conteúdo e conhecer algumas estratégias pedagógicas.

Com essas reflexões, compreendemos a formação inicial como um ambiente de múltiplas representações, ou seja, representações a respeito do conteúdo, do ser professor e do processo de construção dos saberes docentes.

Com isso, queremos dizer que, ao ingressar em um curso de licenciatura, o aluno já apresenta representações sociais a respeito do ser professor que foram sendo construídas ao longo da sua experiência de vida, as quais podem exercer grande influência e dificultar a formação docente (SALAZAR, 2005; HILGER; MOREIRA, 2016).

A presença de conhecimentos prévios na formação docente se mostra clara na literatura especializada (SALAZAR, 2005; SAVIANI, 2009). A Teoria das Representações Sociais concebe que esses conhecimentos não são apenas individualizados, mas partem de um processo de construção coletiva. Nessa perspectiva, a proposta de uma formação de professores crítica e reflexiva passa pela organização de informações e pela identificação de quais grupos sociais estão 
sendo atendidos ao longo do processo, de forma a estruturar uma abordagem que respeite e atue sobre as representações sociais apresentadas, possibilitando um caminhar em direção ao universo reificado.

Apesar da complexidade do processo de formação docente, pesquisas que analisaram cursos de licenciaturas de todo o Brasil revelam a existência de uma estrutura embasada na racionalidade técnica, na qual basta dominar o conteúdo e expô-lo de forma linear. Essa situação se torna mais preocupante quando somada a outras questões, dentre as quais citamos as seguintes: influências políticas, baixos salários e condições precárias de trabalho. Esses fatores podem apresentar impactos consideráveis na atuação docente e nos resultados da educação (GATTI; BARRETO, 2009; MAGALHÃ̃ES; MAIA; ALVES-MAZZOTTTI, 2010).

Tais reflexões reforçam a relevância que o estudo sobre as representações sociais pode trazer para a formação docente, haja visto que tais representações influenciam desde o domínio dos conteúdos até os conhecimentos e as práticas pedagógicas. Diante do exposto, consideramos mister a identificação das representações sociais e da influência que a formação inicial exerce sobre elas. Isso significa um passo necessário do debate sobre a formação de professores que temos e da que desejamos.

\section{ABORDAGEM METODOLÓGICA}

Este trabalho faz parte de um projeto aprovado e financiado pelo Conselho Nacional de Desenvolvimento Científico e Tecnológico (CNPq), por meio do Edital Universal do CNPq 14/2014, sob registro n. 447784/2014-5, e de um projeto de doutoramento em andamento. Trata-se de uma pesquisa qualitativa, que se insere nos estudos do cotidiano. Entre as formas de abordagem das representações sociais, adotamos uma perspectiva estruturalista (ABRIC, 2000), tendo em vista a análise organizacional e hierárquica sobre as representações sociais.

Objetivamos, por meio da técnica de evocação livre de palavras (SÁ, 2000), identificar o núcleo central e a periferia das representações sociais de licenciandos ingressantes e de concluintes do curso de Física das instituições INSTITUIÇÃO 01 e INSTITUIÇÃO 02, sediadas, respectivamente, no Norte e no Oeste do estado do Paraná.

A opção por essa técnica deve-se ao fato de ela permitir ao sujeito apresentar termos que venham à sua mente de maneira espontânea, seja de forma oral, seja de forma escrita. Por isso, os licenciandos que participaram da pesquisa foram estimulados, pelo termo indutor 'ser professor de Física', a escreverem as cinco primeiras palavras que viessem à sua mente em relação ao tema; posteriormente,classificaram essas palavras de acordo com o grau de importância que atribuem a cada uma delas, como sugerem Magalhães Júnior e Tomanik (2012). Finalmente, dos participantes foi solicitada a escrita de pequenos textos os quais deviam explicar o que significavam as palavras evocadas.

Já a escolha das instituições se deve ao fato de ambas ofertarem o curso de licenciatura em Física, com turmas ingressantes e turmas concluintes à época da coleta de dados. Outro fator que motivou a realização da pesquisa nessas instituições foi a autorização dada pelos coordenadores dos referidos cursos e pelos docentes 
das disciplinas em que ocorreram a coleta de dados para a realização da pesquisa com os alunos que, por sua vez, aceitaram participar da pesquisa e autorizaram o uso dos dados coletados.

As duas instituições são públicas e estão localizadas no estado do Paraná. Em ambas, a coleta de dados foi realizada em 2017, sendo que, na INSTITUIÇÃO 01, aconteceu entre os meses de abril e maio e, na INSTITUIÇÃO 02, ocorreu durante o mês de setembro.

Quanto aos participantes da pesquisa, 25 são alunos ingressantes do curso de licenciatura em Física da INSTITUIÇÃO 01, sendo 20 do gênero masculino, quatro do gênero feminino e um apresentou resposta indefinida em relação a esse dado. Entre os participantes concluintes do curso de licenciatura em Física da INSTITUIÇÃO 01, encontram-se dez alunos, sendo sete do gênero masculino e três do gênero feminino. A idade média dos ingressantes é de 18 (17,91 +/- 0,55) anos, enquanto entre os concluintes a média é de 24 (23,55 +/-1,60) anos.

$\mathrm{Na}$ INSTITUIÇÃO 02, a pesquisa contou com a participação de 14 alunos ingressantes, dos quais dez do gênero masculino e quatro do gênero feminino, e 5 alunos concluintes, sendo dois do gênero masculino e três do gênero feminino. Nessa instituição os ingressantes se encontravam na faixa etária média de 22 anos (22,14 + /4,50); já a média de idade dos concluintes era de 20 anos (20,8+/-0,32). Sobre a idade dos participantes, chamamos atenção para o fato de a idade média dos ingressantes ser superior devido a uma variação maior, ou seja, a idade oscilou entre 18 e 43 anos.

A análise dos termos foi realizada por meio da combinação de duas técnicas, como proposto por Pardal et al. (2014). Inicialmente, as palavras foram organizadas em grupos semânticos homogêneos, respeitando-se os princípios da análise de conteúdo (BARDIN, 2002). Para tanto, levamos em consideração as palavras evocadas e o significado apresentado para elas nas redações dos sujeitos da pesquisa.

Na sequência, identificamos a ordem média de evocações (OME), juntamente com a frequência, de forma a construirmos o quadro de quatro casas, identificando elementos do núcleo central e da periferia das representações (MAGALHÃES JÚNIOR; TOMANIK, 2012; GALVÃO; MAGALHÃES JÚNIOR, 2016).

A frequência (f) de cada grupo semântico é dada pelo número de palavras que nele se enquadram. Já a OME é calculada de acordo com a equação apresentada na Figura 1, na qual $P$ representa o número de vezes que uma palavra foi evocada com determinado grau de importância; G representa este grau de importância; $f$ representa a frequência daquele grupo semântico. 
Figura 1. Equação para o cálculo da frequência.

$$
O M E=\sum_{1}^{n} P \cdot G / f
$$

Fonte: GALVÃO; MAGALHÃES JÚNIOR, 2016.

A média das frequências (F), e a média das OME foram obtidas mediante a divisão dessas grandezas pelo número de grupos semânticos estruturados (CORTES JUNIOR; CORIO; FERNANDEZ, 2009; GALVÃO; MAGALHÃES JÚNIOR, 2016).

\section{RESULTADOS E DISCUSSÕES}

Para que possamos realizar, de forma ampla, a discussão sobre as representações sociais identificadas nos grupos investigados, inicialmente apresentamos o perfil e a proposta dos cursos de licenciatura em Física aos quais pertencem os sujeitos da pesquisa. A intenção é evidenciarmos a situação e o ambiente da coleta dos dados, haja vista que as representações sociais se constroem no contexto em que os sujeitos de um determinado grupo estão inseridos.

$\mathrm{Na}$ sequência, apresentamos o quadro de quatro casas que compõe as possíveis representações sociais dos ingressantes e concluintes dos cursos de licenciatura em Física da INSTITUIÇÃO 01 e da INSTITUIÇÃO 02 que participaram da pesquisa. Para desenvolvermos esse procedimento, a organização semântica das palavras foi realizada por meio dos princípios da Análise de Conteúdo (BARDIN, 2002). Essa organização está explicitada no Quadro 1. 
Quadro 1. Grupos semânticos formados após a análise das palavras evocadas pelos licenciandos em Física

\begin{tabular}{|c|c|}
\hline Grupos semânticos & Elementos relacionados \\
\hline Conhecimento Geral & $\begin{array}{l}\text { Engloba palavras que remetem ao domínio de conhecimentos em geral, } \\
\text { em seus aspectos conceituais, teóricos, metodológicos e epistemológicos. } \\
\text { Ex.: Filosofia, Astronomia, energia, conhecimento, conteúdo e teoria. }\end{array}$ \\
\hline $\begin{array}{l}\text { Conceitos } \\
\text { epistemológicos }\end{array}$ & $\begin{array}{l}\text { Concentram palavras que abordam explicitamente perspectivas } \\
\text { epistemológicas do conhecimento. Ex.: racionalismo, empirismo e método } \\
\text { científico. }\end{array}$ \\
\hline $\begin{array}{l}\text { Relevância do } \\
\text { conhecimento físico }\end{array}$ & $\begin{array}{l}\text { Este grupo contempla palavras que representam o conhecimento físico em } \\
\text { uma perspectiva instrumentalista, ou seja, em seu papel e em sua relevância } \\
\text { para o progresso da sociedade. Ex.: tecnologia, saúde e importância. }\end{array}$ \\
\hline Desejo de aprender & $\begin{array}{l}\text { Neste grupo, estão organizadas as palavras que se relacionam à } \\
\text { determinação, à capacidade e ao interesse pessoal do professor em } \\
\text { buscar ou em construir seu conhecimento. Ex.: aprender, curiosidade, } \\
\text { inteligente e nerd. }\end{array}$ \\
\hline Performance docente & $\begin{array}{l}\text { As palavras aqui organizadas dizem respeito à atuação docente em sala } \\
\text { de aula em uma perspectiva do professor como centro do processo. Ex.: } \\
\text { carisma, explicações, elegante e transmissão do conhecimento. }\end{array}$ \\
\hline Atividades práticas & $\begin{array}{l}\text { Este grupo engloba termos que remetem à importância e ao uso de } \\
\text { atividades práticas para o ensino de Física. Ex.: laboratório, experimentos } \\
\text { e demonstração. }\end{array}$ \\
\hline $\begin{array}{l}\text { Conhecimento de } \\
\text { práticas pedagógicas }\end{array}$ & $\begin{array}{l}\text { Neste grupo, contemplam-se as palavras que se relacionam ao } \\
\text { conhecimento teórico e prático de conceitos de didática necessários à } \\
\text { atuação docente. Ex.: didática. }\end{array}$ \\
\hline $\begin{array}{l}\text { Comportamento } \\
\text { docente }\end{array}$ & $\begin{array}{l}\text { Aqui foram organizadas as palavras que se relacionam ao professor em } \\
\text { uma perspectiva de reflexão a respeito de seu papel e de sua prática. Ex.: } \\
\text { responsabilidade, eficiência, educar e dedicação. }\end{array}$ \\
\hline Motivação pessoal & $\begin{array}{l}\text { Neste grupo, estão reunidos termos que indicam desejos ou características } \\
\text { pessoais que influenciam na escolha da profissão. Ex.: apreço, talento, } \\
\text { prazer e vocação. }\end{array}$ \\
\hline $\begin{array}{l}\text { Externalidades e } \\
\text { dificuldades }\end{array}$ & $\begin{array}{l}\text { Organiza as palavras que indicam incômodo ou sentimentos negativos } \\
\text { em relação à profissão devido a fatores externos. Ex.: estresse, greve, } \\
\text { governo, salário e miséria. }\end{array}$ \\
\hline $\begin{array}{l}\text { Influências } \\
\text { externas (síntese } \\
\text { do grupo motivação } \\
\text { pessoal e do grupo } \\
\text { externalidades e } \\
\text { dificuldades) }\end{array}$ & $\begin{array}{l}\text { Este grupo foi criado para organizar palavras e conceitos que se mostram } \\
\text { como dificuldade e, ao mesmo tempo, como motivação ao docente. } \\
\text { A diferença em relação aos outros dois grupos é que, nesse caso, as } \\
\text { palavras não carregam características necessariamente positivas ou } \\
\text { negativas. Ex.: desafio. }\end{array}$ \\
\hline $\begin{array}{l}\text { Interação com os } \\
\text { alunos }\end{array}$ & $\begin{array}{l}\text { Este grupo reúne palavras que expressam a preocupação de o docente } \\
\text { interagir com o aluno de forma a incentivá-lo a participar dos s de ensino e } \\
\text { de aprendizagem. Ex.: provocação, interativo e motivar. }\end{array}$ \\
\hline $\begin{array}{l}\text { Afetividade com os } \\
\text { alunos }\end{array}$ & $\begin{array}{l}\text { Trata-se de um conjunto de palavras que representam sentimentos, } \\
\text { cuidados e reflexões que podem influenciar a prática pedagógica. Ex.: } \\
\text { empatia, respeito e paciência. }\end{array}$ \\
\hline
\end{tabular}

Fonte: Os autores. 
No caso dos alunos da INSTITUIÇÃO 01, foi possível estruturar 11 grupos semânticos para os ingressantes e nove para os concluintes. Já na INSTITUIÇÃO 02, foram organizados 12 grupos para os ingressantes e nove grupos para os concluintes.

\section{O CURSO DE LICENCIATURA EM FÍSICA DA INSTITUIC̣ÃO 01}

As informações disponíveis no site da INSTITUIÇÃO 01 indicam que o Curso de Licenciatura em Física teve início em 1973, com três diferentes currículos. Duas alterações foram realizadas no seu Projeto Pedagógico, sendo que, em 1992, foi adotado o regime anual, quando o currículo dos dois primeiros anos passou a ser comum ao bacharelado e à licenciatura. No terceiro ano, o graduando opta pela modalidade que deseja seguir. A segunda alteração foi realizada em 2001, com o objetivo de atender à nova legislação referente à formação de professores, entretanto sem alterar o modelo de oferta (2+2) (DEPARTAMENTO de Física, s.d.).

O Curso de Licenciatura em Física da INSTITUIÇÃO 01 se propõe a formar um profissional com perfil de físico-educador. No que diz respeito às competências e às habilidades esperadas, o curso apresenta nove competências gerais e cinco competências específicas para o físico-educador. Já em relação às habilidades, identificam-se 17 gerais e duas específicas para esse profissional.

Enfim, o website do curso apresenta o campo de atuação dos egressos em Física. Nesse aspecto, não há a diferenciação entre o bacharel e a licenciado, sendo que, de acordo com a instituição, os graduados no curso de Física podem desde ensinar Física até atuar na indústria e no setor de inovação tecnológica.

\section{O CURSO DE LICENCIATURA EM FÍSICA DA INSTITUIC̣ÃO 02}

No caso da INSTITUIÇÃO 02, de acordo com as informações disponíveis no seu site, o Curso de Licenciatura em Física surgiu da demanda regional por professores de Física. Sua concepção preza por uma formação teórica, científica e tecnológica, além de humanística e crítico-pedagógica. O curso tem sua grade curricular organizada em quatro anos, possuindo componentes pedagógicos distribuídos em todas as séries.

No que se refere ao perfil do egresso, a INSTITUIÇÃO 02 também se propõe a formar um físico-educador. Para tanto, elenca nove habilidades gerais, cinco habilidades específicas e cinco competências específicas ao físico-educador.

Para definir a atuação profissional do seu egresso, o Projeto Pedagógico do Curso de Licenciatura em Física da INSTITUIÇÃO 02 ampara-se no Parecer 1.304/2001 - CNE/CES (BRASIL, 2001), definindo a educação básica e a educação superior como espaços para o exercício da docência o desenvolvimento de projetos de educação não formal e a produção de material pedagógico na área do ensino de Física (INSTITUIÇÃO 02, s.d.). 


\section{REPRESENTACִÕES SOCIAIS DE INGRESSANTES E DE CONCLUINTES DE LICENCIATURA EM FÍSICA DA INSTITUIĈ̣̃O 01}

Entre os ingressantes no curso, a OME média e a frequência média foram, respectivamente, 3,11 e 11,09. Foram evocadas 125 palavras, tendo sido descartadas três delas por terem apresentado frequência igual a um, o que não confere importância à representatividade do grupo (MAGALHÃES JÚNIOR; TOMANIK, 2012).

Com esses valores, traçamos o quadro de quatro casas, delimitando os elementos centrais, os intermediários e os periféricos das representações sociais desse grupo, conforme demonstra o Quadro 2. Esse quadro é construído da seguinte maneira: no primeiro quadrante, encontram-se os grupos semânticos que apresentam alta frequência e baixa $\mathrm{OME}^{1}$ - elementos considerados o núcleo central das representações sociais.

No segundo quadrante, estão os grupos semânticos com alta frequência, seguidos dos de alta OME, sendo definidos como a primeira periferia, ou seja, elementos de proteção e de contextualização das representações sociais que se encontram mais próximas ao núcleo central.

O terceiro quadrante guarda elementos de baixa frequência e de baixa OME. Isso implica que esses grupos podem estruturar um núcleo de representação de alguns dos membros do grupo, o qual não é generalizado como o núcleo central.

Finalmente, o quarto quadrante reúne os elementos mais externos das representações sociais, os quais apresentam baixa frequência e alta OME. Esse quadrante é definido como segunda periferia e atua de forma mais direta nas experiências cotidianas e conflitantes das representações.

Quadro 2. Quadro de quatro casas para os ingressantes na licenciatura em Física da INSTITUIĈ̣̃O 01 para 0 termo indutor "ser professor de Física"

\begin{tabular}{|c|c|c|c|c|c|}
\hline \multicolumn{3}{|c|}{ Elementos centrais - $1^{\circ}$ quadrante } & \multicolumn{3}{|c|}{ Elementos intermediários $-2^{\circ}$ quadrante } \\
\hline \multicolumn{3}{|c|}{$\begin{array}{l}\text { Alta f e baixa Ordem Média de Evocações } \\
\qquad \mathrm{f} \geqslant 11,09 \text { e } \mathrm{OME}<3,11\end{array}$} & \multicolumn{3}{|c|}{$\begin{array}{l}\text { Alta f e alta Ordem Média de Evocações } \\
\qquad f \geqslant 11,09 \text { e } 0 M E \geqslant 3,11\end{array}$} \\
\hline Palavra & Freq. & OME & Palavra & Freq. & OME \\
\hline Conhecimento geral & 22 & 2,63 & Performance docente & 13 & 3,30 \\
\hline Comportamento docente & 13 & 2,38 & & & \\
\hline Motivação pessoal & 15 & 3,06 & & & \\
\hline Desejo de aprender & 12 & 2,58 & & & \\
\hline \multicolumn{3}{|c|}{ Elementos intermediários $-3^{\circ}$ quadrante } & \multicolumn{3}{|c|}{ Elementos periféricos $-4^{\circ}$ quadrante } \\
\hline \multicolumn{3}{|c|}{$\begin{array}{l}\text { Baixa f e baixa Ordem Média de Evocações } \\
\qquad f<11,09 \text { e } 0 M E<3,11\end{array}$} & \multicolumn{3}{|c|}{$\begin{array}{l}\text { Baixa f e alta Ordem Média de Evocações } \\
\qquad f<11,09 \text { e } 0 M E \geqslant 3,11\end{array}$} \\
\hline Palavra & Freq. & OME & Palavra & Freq. & OME \\
\hline $\begin{array}{l}\text { Conhecimento de práticas } \\
\text { pedagógicas }\end{array}$ & 8 & 2,00 & $\begin{array}{l}\text { Relevância do conhecimento } \\
\text { físico }\end{array}$ & 5 & 4,8 \\
\hline \multirow[t]{3}{*}{ Externalidades e dificuldades } & 8 & 3,00 & Interação com o aluno & 7 & 3,42 \\
\hline & & & Afetividade com o aluno & 6 & 3,33 \\
\hline & & & Atividades práticas & 9 & 3,77 \\
\hline
\end{tabular}

Fonte: Os autores. 
O primeiro quadrante representa o possível núcleo central das representações sociais dos licenciandos. O terceiro quadrante contempla elementos do núcleo das representações de algumas pessoas do grupo, as quais não são compartilhadas por todos. O segundo quadrante identifica a primeira periferia, enquanto o quarto quadrante contempla a segunda periferia das representações (HILGER; STIPCICH; MOREIRA, 2017).

Por meio dessa análise, os elementos que compõem o núcleo central das representações são 'conhecimento geral', 'comportamento docente', 'motivação pessoal' e 'desejo de aprender'.

Esses elementos indicam uma perspectiva tradicionalista de ensino centrada no professor. Por um lado, há uma preocupação em refletir a respeito da própria prática, caracterizada pelo grupo semântico 'comportamento docente'; por outro lado, 'ser professor de Física’ apresenta relação com dominar o conteúdo e possuir motivações pessoais, enquanto o conhecimento do contexto, o conhecimento pedagógico e o conhecimento dos alunos não se fazem presentes.

Tais resultados conformam-se aos resultados apresentados por Ortiz e Magalhães Júnior (2017) e se aproximam do professor tradicional e positivista. Nessa perspectiva, o domínio do conteúdo e o bom senso são suficientes para transmitir ao aluno as informações necessárias (BEHRENS, 2013; SAVIANI, 2009).

Esses resultados contradizem a complexidade necessária à formação docente, que inter-relaciona conhecimentos teóricos e práticos, conceituais e pedagógicos (SALAZAR, 2005; SAVIANI, 2009; SHULMAN, 1986; 1987).

Já a periferia dessas representações é composta pelos elementos 'relevância do conhecimento físico', ‘interação com o aluno’, ‘afetividade com o aluno’ e 'atividades práticas'.

Trata-se de elementos significativos para o trabalho docente, tanto em relação à contextualização, quanto no que concerne à motivação e à afetividade com os alunos no processo de aprendizagem (SHULMAN, 1986; 1987; TASSONI; LEITE, 2013). Entretanto não podemos ignorar que os elementos da periferia não dão significado à representação social, bem como não são estáveis, cabendo a si proteger o núcleo central (ABRIC, 2000).

Os concluintes do curso evocaram 50 palavras, sendo que nenhuma foi descartada. Nesse caso, a OME foi 3,17 e a frequência média (F) de 5,55.

Para a organização dessas palavras em grupos semânticos, não foi necessário criar um novo grupo, pois elas se enquadravam naqueles já utilizados com os ingressantes. Essas informações estão sistematizadas no Quadro 3 quadro de quatro casas para esse grupo. 
Quadro 3. Quadro de quatro casas para os concluintes Do Curso de Licenciatura em Física da INSTITUIÇ̃̃O 01 para o termo indutor "ser professor de Física"

\begin{tabular}{|c|c|c|c|c|c|}
\hline \multicolumn{3}{|c|}{ Elementos centrais $-1^{\circ}$ quadrante } & \multicolumn{3}{|c|}{ Elementos intermediários $-2^{\circ}$ quadrante } \\
\hline \multicolumn{3}{|c|}{$\begin{array}{l}\text { Alta f e baixa Ordem Média de Evocações } \\
\qquad>5,55 \text { e } \mathrm{OME}<3,17\end{array}$} & \multicolumn{3}{|c|}{$\begin{array}{l}\text { Alta f e alta Ordem Média de Evocações } \\
\qquad f>5,55 \text { e } 0 M E \geqslant 3,17\end{array}$} \\
\hline Palavra & freq. & OME & Palavra & freq. & OME \\
\hline Comportamento docente & 7 & 2,57 & Interação com o aluno & 8 & 4,62 \\
\hline Conhecimento geral & 13 & 2,69 & & & \\
\hline Motivação pessoal & 6 & 2,16 & & & \\
\hline Afetividade com o aluno & 7 & 2,57 & & & \\
\hline \multicolumn{3}{|c|}{ Elementos intermediários - $3^{\circ}$ quadrante } & \multicolumn{3}{|c|}{ Elementos periféricos $-4^{\circ}$ quadrante } \\
\hline \multicolumn{3}{|c|}{$\begin{array}{l}\text { Baixa } f \text { e baixa } 0 M E \\
f<5,55 \text { e } 0 M E<3,17\end{array}$} & \multicolumn{3}{|c|}{$\begin{array}{l}\text { Baixa f e alta Ordem Média de Evocações } \\
\qquad<<5,55 \text { e } 0 M E \geqslant 3,17\end{array}$} \\
\hline Palavra & freq. & OME & Palavra & freq. & OME \\
\hline Performance docente & 2 & 2,66 & Desejo de aprender & 3 & 3,33 \\
\hline $\begin{array}{l}\text { Conhecimento de práticas } \\
\text { pedagógicas }\end{array}$ & 2 & 3 & Externalidades e dificuldades & 1 & 5 \\
\hline
\end{tabular}

Fonte: Os autores.

Nos concluintes do curso, os elementos que, possivelmente, pertencem ao núcleo central são os seguintes: 'comportamento docente', 'conhecimento geral', 'motivação pessoal' e 'afetividade com o aluno'. Já a periferia é composta pelos seguintes termos: 'desejo de aprender' e 'externalidades e dificuldades'.

O núcleo das representações não apresenta grandes alterações, possuindo como novo elemento a 'afetividade com o aluno'. Isso indica uma mudança de perspectiva no que se refere à interação professor-conteúdo-aluno (TASSONI; LEITE, 2013).

Apesar de tal alteração, esse núcleo permanece centrado em uma perspectiva tradicional de ensino. Elementos relativos à contextualização, bem como aos conhecimentos pedagógicos não são identificados, salvo a afetividade.

Enquanto isso, a presença das 'externalidades e dificuldades' na periferia reforça sua composição por elementos mais acessíveis e concretos, dado que esses são problemas que impactam diretamente o trabalho docente (SAVIANI, 2009).

\section{REPRESENTAÇ̃̃ES SOCIAIS DE INGRESSANTESEDE CONCLUINTES DO CURSO DELICENCIATURA EM FÍSICA DA INSTITUICְ̃̃O 02}

No caso dos ingressantes deste curso, a OME média foi de 3,36 e a frequência média de 6,58. Foram evocadas um total de 80 palavras, sendo que uma foi descartada por apresentar frequência um, conforme exposto anteriormente. Com esses valores elaboramos o Quadro 4, apresentado a seguir. 
Quadro 4. Quadro de quatro casas para os ingressantes no Curso de Licenciatura em Física INSTITUIĈ̣̃O 02 para o termo indutor "ser professor de Física"

\begin{tabular}{|c|c|c|c|c|c|}
\hline \multicolumn{3}{|c|}{ Elementos centrais $-1^{\circ}$ quadrante } & \multicolumn{3}{|c|}{ Elementos intermediários - $2^{\circ}$ quadrante } \\
\hline \multicolumn{3}{|c|}{$\begin{array}{l}\text { Alta f e baixa Ordem Média de Evocações } \\
\qquad f>6,58 \text { e } \mathrm{ME}<3,36\end{array}$} & \multicolumn{3}{|c|}{$\begin{array}{l}\text { Alta f e alta Ordem Média de Evocações } \\
\qquad f>6,58 \text { e } 0 M E \geqslant 3,36\end{array}$} \\
\hline Palavra & Freq. & OME & Palavra & Freq. & OME \\
\hline Conhecimento geral & 21 & 3,28 & - & & \\
\hline Desejo de aprender & 9 & 3,00 & & & \\
\hline Comportamento docente & 8 & 1,87 & & & \\
\hline Motivação pessoal & 8 & 2,43 & & & \\
\hline Externalidades e dificuldades & 8 & 3,00 & & & \\
\hline \multicolumn{3}{|c|}{ Elementos intermediários - $3^{\circ}$ quadrante } & \multicolumn{3}{|c|}{ Elementos periféricos $-4^{\circ}$ quadrante } \\
\hline \multicolumn{3}{|c|}{$\begin{array}{l}\text { Baixa f e baixa Ordem Média de Evocações } \\
\qquad \mathrm{f}<6,58 \text { e } \mathrm{OME}<3,36\end{array}$} & \multicolumn{3}{|c|}{$\begin{array}{l}\text { Baixa f e alta Ordem Média de Evocações } \\
\qquad f<6,58 \text { e } 0 M E \geqslant 3,36\end{array}$} \\
\hline Palavra & Freq. & OME & Palavra & Freq. & OME \\
\hline Performance docente & 6 & 3,17 & Conceitos epistemológicos & 5 & 3,80 \\
\hline \multirow[t]{4}{*}{ Atividades práticas } & 3 & 2,33 & $\begin{array}{l}\text { Relevância do } \\
\text { conhecimento Físico }\end{array}$ & 3 & 5,67 \\
\hline & & & $\begin{array}{l}\text { Conhecimento de práticas } \\
\text { pedagógicas }\end{array}$ & 2 & 4,00 \\
\hline & & & Interação com o aluno & 3 & 4,33 \\
\hline & & & Afetividade com o aluno & 4 & 3,50 \\
\hline
\end{tabular}

Fonte: Os autores.

O núcleo das representações desses sujeitos é composto por conceitos relativos ao conhecimento do conteúdo, bem como por influências externas, sejam elas positivas (motivação) ou negativas (externalidades).

Tais resultados se aproximam daqueles identificados entre os ingressantes da INSTITUIÇÃO 01. Novamente, a presença do grupo 'comportamento docente' aponta que há, entre esses licenciandos, uma preocupação em refletir a respeito da sua prática. Entretanto os outros grupos que compõem o núcleo central indicam a falta de elementos que possam facilitam essa reflexão, dados que reforçam uma representação de professor como aquele que "domina o conteúdo" e "possui bom senso", ou seja, de professor que transmite o conhecimento, sustentando sua prática na racionalidade técnica (ORTIZ; MAGALHÃES JÚNIOR, 2017; BEHRENS, 2013; SAVIANI, 2009).

Além disso, a presença do grupo 'externalidades e dificuldades' no núcleo chama a atenção, já que os respondentes são ingressantes do curso. $\mathrm{O}$ trabalho de Lunkes e Rocha Filho (2011) traz indícios de que essas representações podem prejudicar a procura por cursos de Licenciatura em Física, já que o status social dos professores, somado à mensagens negativas comunicadas ao longo do ensino 
médio, amplia a má impressão relativa à carreira docente. Tal resultado alerta ainda para o fato de que as condições de trabalho, as decisões governamentais e o nível salarial podem influenciar não apenas a prática docente, mas também a formação de professores, como afirma Saviani (2009).

Enquanto isso, elementos relativos ao conhecimento pedagógico e contextual compõem a periferia das representações sociais. Apesar de estarem presentes, esses elementos não estão sedimentados nelas, podendo ser substituídos, com facilidade, em comparação ao núcleo central, o que indica menor impacto na interpretação dada ao professor de Física por esse grupo.

Quanto aos alunos concluintes, a OME média foi de 2,96, enquanto a F identificada foi de 3,67, conforme resultados apresentados no Quadro 5. No total, foram evocadas 25 palavras, tendo sido descartadas três delas, cuja frequência foi igual a um e, por isso, não são relevantes para a representatividade do grupo.

Quadro 5. Quadro de quatro casas para os concluintes do Curso de Licenciatura em Física da INSTITUIC̣ÃO 02 para o termo indutor "ser professor de Física"

\begin{tabular}{|c|c|c|c|c|c|}
\hline \multicolumn{3}{|c|}{ Elementos centrais $-1^{\circ}$ quadrante } & \multicolumn{3}{|c|}{ Elementos intermediários $-2^{\circ}$ quadrante } \\
\hline \multicolumn{3}{|c|}{$\begin{array}{l}\text { Alta f e baixa Ordem Média de Evocações } \\
\qquad f>3,67 \text { e OME }<2,96\end{array}$} & \multicolumn{3}{|c|}{$\begin{array}{l}\text { Alta f e alta Ordem Média de Evocações } \\
\qquad f>3,67 \text { e OME } \geqslant 2,96\end{array}$} \\
\hline Palavra & Freq. & OME & Palavra & Freq. & OME \\
\hline Conhecimento Geral & 4 & 2,5 & - & & \\
\hline Comportamento docente & 9 & 2,78 & & & \\
\hline \multicolumn{3}{|c|}{ Elementos intermediários $-3^{\circ}$ quadrante } & \multicolumn{3}{|c|}{ Elementos periféricos - $4^{\circ}$ quadrante } \\
\hline \multicolumn{3}{|c|}{$\begin{array}{l}\text { Baixa f e baixa Ordem Média de Evocações } \\
\qquad f<3,67 \text { e } \mathrm{OME}<2,96\end{array}$} & \multicolumn{3}{|c|}{$\begin{array}{l}\text { Baixa f e alta Ordem Média de Evocações } \\
\qquad f<3,67 \text { e } O M E \geqslant 2,96\end{array}$} \\
\hline Palavra & Freq. & OME & Palavra & Freq. & OME \\
\hline $\begin{array}{l}\text { Conhecimento de práticas } \\
\text { pedagógicas } \\
\text { Influências externas }\end{array}$ & 3 & 2 & $\begin{array}{l}\text { Interação com o aluno } \\
\text { Performance Docente }\end{array}$ & $\begin{array}{l}2 \\
2\end{array}$ & $\begin{array}{c}3,5 \\
4\end{array}$ \\
\hline
\end{tabular}

Fonte: Os autores.

Nesse caso, identificamos que os elementos que compõem as representações sociais ficaram mais específicos. O núcleo central é composto por elementos relativos ao conhecimento geral e ao comportamento docente, enquanto, na periferia, estão a interação com o aluno e a performance docente. Conceitos relacionados aos conhecimentos pedagógicos saíram da periferia e se tornaram elementos intermediários, todavia sem compor ainda o núcleo das representações. 
Nesse contexto, novamente o núcleo permanece centrado no domínio do conteúdo e na reflexão a respeito da prática docente. Esses grupos reforçam as considerações apresentadas pelos ingressantes. Há uma preocupação em refletir sobre a prática docente, entretanto elementos essenciais à essa reflexão, como os conhecimentos pedagógicos, o contexto e os alunos não se encontram sedimentados em suas representações.

Uma alteração identificada é que elementos relativos às externalidades, quer sejam positivas, quer sejam negativas, deixaram de compor o núcleo das representações; isso é um indicativo de que se mostram bem menos significativas à perspectiva do trabalho docente nos concluintes do curso.

Tanto no caso dos ingressantes quanto no dos concluintes da INSTITUIÇÃO 02, chama-nos atenção o fato de não terem sido identificados elementos relativos ao segundo quadrante. Nessa posição, encontra-se a primeira periferia (HILGER; STIPCICH; MOREIRA, 2017), ou seja, conceitos que atuam como proteção e sustentação do núcleo central, da mesma forma que os identificados no quarto quadrante. Essa é uma temática para trabalhos futuros, considerando-se que ainda não possuímos elementos que possam explicar tal fenômeno. Por outro lado, esses dados não trazem impacto às nossas análises, haja visto que os elementos do núcleo central são os que nos permitem compreender se houve diferença e possíveis alterações entre as representações sociais dos grupos investigados (ABRIC, 2000).

\section{UM OLHAR SOBRE AS REPRESENTAÇÕES SOCIAIS APRESENTADAS}

Como indicado anteriormente, o conhecimento necessário ao trabalho docente envolve o conteúdo, as práticas pedagógicas, o conhecimento contextual e o conhecimento sobre o aluno. Além de saber se expressar e dominar o conteúdo, o professor precisa manifestar afetividade com os alunos, bem como construir um ambiente que evidencie o educando como o centro dos processos de ensino e de aprendizagem (ORTIZ; MAGALHÃES JÚNIOR, 2017; BEHRENS, 2013; TASSONI; LEITE, 2013; SHULMAN, 1986; 1987).

Além disso, elementos externos - o status social, os salários e a carga horária - exercem influência sobre o trabalho docente, tanto no que se refere à construção da prática pedagógica quanto no que diz respeito à representação formada pelos alunos ao longo da educação básica (SAVIANI, 2009; LUNKES; ROCHA FILHO, 2011).

Entretanto, em ambos os casos investigados, há indícios da ausência de alguns conhecimentos do universo reificado, principalmente pedagógicos, no núcleo central das representações.

No caso da INSTITUIÇÃO 01, surgem, entre os formandos, conceitos relativos à afetividade, o que indica uma alteração progressiva de suas representações (ABRIC, 2000), porém não há rupturas.

Já no curso da INSTITUIÇÃO 02, os conhecimentos pedagógicos se deslocam da periferia para um quadrante intermediário, ainda sem compor o 
núcleo das representações. Novamente, esses resultados apresentam indícios de um processo de alteração reversível ou progressiva nas representações sociais desses sujeitos (ABRIC, 2000).

Essas representações reiteram resultados anteriores que apresentam uma perspectiva tradicionalista sobre o professor (ORTIZ; MAGALHÃES JÚNIOR, 2017; BEHRENS, 2013; MAGALHÃES; MAIA; ALVES-MAZZOTTI, 2010). Por outro lado, observamos que conceitos como 'performance docente' caminharam em direção à periferia das representações dos concluintes, o que, do nosso ponto de vista, é um fator positivo, pois representa uma descentralização do professor nos processos de ensino e de aprendizagem.

Questões externas que podem influenciar o trabalho docente também foram identificadas em ambas as instituições, sendo que as positivas, ligadas à motivação pessoal, encontram posição no núcleo central de três dos grupos investigados (apenas os concluintes da INSTITUIÇÃO 02 não apresentam esse grupo semântico), enquanto as negativas, referentes à desvalorização e às dificuldades encontradas ao longo da vida profissional, estão presentes apenas no núcleo dos ingressantes da INSTITUIÇÃO 02. Além disso, em ambos os casos, as externalidades negativas perdem representatividade entre os concluintes, deslocando-se para mais próximo da periferia externa. Dessa forma, é possível inferir que, nos grupos investigados, as questões sociais positivas apresentam maior impacto na construção das representações sociais a respeito do professor de Física do que as possíveis frustrações e desafios normalmente vinculados ao trabalho docente.

A análise de tais resultados à luz da Teoria das Representações Sociais revela que os grupos investigados não sofreram alterações significativas no núcleo das suas representações sociais ao longo da sua formação inicial, o que reforça a dificuldade inerente a alterações estruturais de uma representação (ABRIC, 2000).

Notamos que todos os grupos investigados apresentaram, em seu núcleo, elementos relativos ao 'comportamento docente'. Isso implica que os licenciandos preocupam-se em refletir a respeito de sua prática e em buscar estratégias que possibilitem a aprendizagem dos alunos.

Essa preocupação, entretanto, pode gerar prejuízos à formação docente, visto que não estão solidificados conceitos relativos aos conhecimentos pedagógicos, ao contexto e aos alunos, aspectos fundamentais para a caracterização do trabalho docente (SALAZAR, 2005; SHULMAN, 1986; 1987).

Além disso, a presença constante de elementos externos positivos como a motivação pessoal pode exercer influência negativa, uma vez que, sem outros conhecimentos essenciais para a formação docente, tal como apontamos anteriormente, pode acabar reforçando a percepção da docência como um dom ou uma arte, ou seja, algo inerente ao sujeito.

É relevante atentar-se para essa faceta, pois tais elementos de representação fizeram-se presentes em todos os grupos investigados na nossa pesquisa, quer seja nos grupos de ingressantes, quer seja nos grupos de concluintes, apesar de eles se mostrarem diluídos entre os elementos negativos - no grupo semântico 'influências externas' - e estarem em um quadrante intermediário, no caso dos concluintes da INSTITUIÇÃO 02. 
A semelhança de resultados entre os grupos de duas instituições distantes geograficamente e com modelos de formação distintos reforçam a presença de uma perspectiva positivista, bem como da concepção de habilidade docente como algo inerente ao professor nos processos de ancoragem e de objetivação do conceito 'professor de Física' nos sujeitos investigados (MOSCOVICI, 2015). Isso nos leva a inferir que o contexto de formação inicial não trouxe impactos significativos na construção de saberes dos sujeitos da pesquisa a respeito de 'ser professor de Física'.

Compreendemos, assim, que apenas a alteração curricular, substituindo a organização tradicional 3+1 pela inserção de conhecimentos e práticas pedagógicas ao longo de todo o curso, não resulta, necessariamente, em um ambiente propício a alterações nas representações sociais e na construção de PCK.

De acordo com Abric (2000), a forma como as alterações das representações ocorrem depende do quão contraditórias são as práticas às quais um grupo é exposto. Ao trazermos essa perspectiva para a reflexão sobre a formação de professores, reforçamos os posicionamentos de autores como Shulman (1986, 1987), Saviani (2009), Behrens (2013), entre outros, que indicam a necessidade de uma formação docente ampla, isto é, uma formação que considera não apenas o domínio do conteúdo, mas também o domínio de conhecimentos pedagógicos, o contexto e os próprios alunos.

\section{CONSIDERACְÕES FINAIS}

Este trabalho é parte de uma ampla pesquisa que busca compreender as representações sociais de ingressantes e de concluintes de cursos de licenciatura e de professores da área de Ciências Naturais. Voltamos nosso olhar para a formação inicial em Física, buscando identificar elementos de representações sociais a respeito do 'ser professor de Física'.

Os resultados obtidos indicam que, apesar de possíveis diferenças entre as representações sociais, não houve mudanças significativas no núcleo das representações dos grupos investigados. Nesse sentido, podemos afirmar que as mudanças observadas nas representações sociais dos grupos que fizeram parte dessa pesquisa caracterizam-se como reversíveis ou como progressivas; não houve uma ruptura em suas representações ao longo do processo de formação inicial para a docência, dado que o núcleo das representações sociais dos ingressantes e o dos concluintes permitem compreendê-los como membros do mesmo grupo social.

Isso ocorre em ambas as instituições de ensino que oferecem os cursos de Licenciatura em Física cujos sujeitos da pesquisa estão matriculados, apesar de esses cursos apresentarem propostas curriculares diferentes. Nesse sentido, embora teoricamente se trate de diferentes contextos, houve pouco impacto da formação inicial nas representações dos sujeitos participantes da pesquisa.

Reforçamos, entretanto, que um elemento presente em todos os grupos investigados é o 'comportamento docente', relacionado, nesta pesquisa, a uma prática reflexiva e crítica. Além disso, preocupações externas como o salário e a desvalorização da profissão fazem parte dessas representações, sendo um elemento relevante à motivação pessoal para continuar no exercício da docência. 
Os resultados aqui observados corroboram resultados de pesquisas anteriores presentes na literatura especializada, os quais indicam haver dificuldade de se alterar uma representação social, bem como de predominar uma perspectiva de ensino positivista presente em professores de Física.

É importante destacar que, nos casos dos ingressantes e dos concluintes do Curso de Licenciatura em Física da INSTITUIÇÃ̃O 02, o segundo quadrante do quadro de quatro casas não contemplou qualquer elemento de representações sociais. As consequências de tal resultado indicam um novo caminho de investigação.

Além disso, surgem novas questões, como as seguintes: quais ambientes apresentam impacto na construção das representações sociais sobre o 'ser professor de Física’? Como a licenciatura pode atuar para realizar uma aproximação efetiva entre futuros professores e o universo reificado dos conhecimentos docentes? As representações sociais dos professores formadores sobre o 'ser professor' e o próprio curso impactam nesse cenário? Essas são algumas perguntas que podem contribuir com os resultados, ainda escassos, a respeito das representações sociais na área do Ensino de Física.

\section{REFERÊNCIAS}

ABRIC, J. C. A abordagem estrutural das Representações Sociais. In: MOREIRA, A. S.; OLIVEIRA, D. C. (org.). Estudos interdisciplinares de representação social. Goiânia: Cultura e Qualidade, 2000. p. 18-43.

ALMEIDA JUNIOR, J. B. A evolução do Ensino de Física no Brasil. Revista de Ensino de Física, v.1, n. 2, p. 45-58, 1979. Disponível em: <http://www.sbfisica.org.br/rbef/pdf/vol01a17.pdf>. Acesso em: 10 jan. 2019.

ALVES-MAZZOTTI, A. J. Representações sociais: aspectos teóricos e aplicações à educação. Revista Múltiplas Leituras, Brasília, v.14, n. 61, p. 18-43, 2008.

BARDIN, L. Análise de conteúdo. Tradução de Luís Antero Reto e Augusto Pinheiro. Lisboa: Edições 70, 2002.

BEHRENS, M. A. O paradigma emergente e a prática pedagógica. 6ª ed. Petrópolis: Vozes, 2013.

CORTES JUNIOR, L. P.; CORIO, P.; FERNANDEZ, C. As representações sociais de Química Ambiental dos alunos iniciantes na graduação em Química. Química Nova na Escola, v. 31, n.1, p. 46-54, 2009. Disponível em: <http://qnesc.sbq.org.br/online/qnesc31_1/09-AF-5608.pdf>. Acesso em: 10 jan. 2019.

DEPARTAMENTO de Física - INSTITUIÇÃO 01. (s.d.). INSTITUIÇÃO 01Departamento de Física. (FourTI) Disponível em:<http://site.dfi. INSTITUIÇÃO 01 .br/apresentacao/historico/>. Acesso em: 03 jan. 2019.

GALVÃO, C. B.; MAGALHÃES JÚNIOR, C. A. O. A relação entre as Representações Sociais de professores sobre Educação Ambiental e os projetos relacionados à Conferência Nacional infantojuvenil pelo Meio Ambiente. Revista Eletrônica do Mestrado em Educação Ambiental, Rio Grande, v. 33, n. 2, p.124-141. 2016. Disponível em: < https://periodicos.furg.br/remea/article/ view/5641/3890>. Acesso em: 21 jan. 2019. 
GATTI, B. A.; BARRETO, E. S. Professores do Brasil: impasses e desafios. Brasília: Unesco, 2009.

HILGER, T. R.; MOREIRA., M. A. Uma revisão de literatura sobre trabalhos em representações sociais relacionados ao Ensino de Física. Revista Brasileira de Pesquisa em Educação em Ciências,v.16, n.1, p. 167-186, 2016.

HILGER, T.R.; STIPCICH, M. S.; MOREIRA, M. A. Representações sociais sobre Física Quântica entre estudantes de graduação brasileiros e argentinos. Latin American Journal of Physics Education, v.11, n.1, p.1303-1-1303-9, 2017.

INSTITUIÇÃO 02. (s.d.). PROJETO PEDAGÓGICO DO CURSO DE LICENCIATURA EM FÍSICA. Acesso em 21 de novembro de 2017, disponível em: http:/ INSTITUIÇÃO 02.edu. br/wp-content/uploads/2015/08/PPC-Curso-de-Licenciatura-em-F\%C3\%ADsica.pdf.

LUNKES, M. J.; ROCHA FILHO, J. B. A baixa procura pela licenciatura em Física, com base em depoimentos de estudantes do ensino médio público do Oeste catarinense. Ciência \& Educação, v.17, n.1, p. 21-34, 2011.

MAGALHÃES, E. M. M.; MAIA, H.; ALVES-MAZZOTTI, A. J. Representações sociais de trabalho docente por professores de curso de Pedagogia. Trabalho \& Educação, v.18, n. 2, p. 11-26, 2010. Disponível em: <https://seer.ufmg.br/index.php/trabedu/article/view/7023/5403>. Acesso em: 10 jan. 2019.

MAGALHÃES JÚNIOR, C. A. O.; TOMANIK, E. A. Representações Sociais e direcionamento para a Educação Ambiental na Reserva biológica das Perobas, Paraná. Investigações em Ensino de Ciências, Porto Alegre,v. 17, n. 1, p. 227-248, 2012. disponível em: <https://www.if.ufrgs.br/cref/ ojs/index.php/ienci/article/view/214/148>. Acesso em: 21 jan. 2019.

MONTEIRO, M. A. Discurso de professores e de livros didáticos de Física no nível médio em abordagens sobre o ensino de Física moderna e contemporânea: algumas implicações educacionais. 2010. 439f. Tese (Doutorado em Educação para a Ciência) - Faculdade de Ciências, Universidade Estadual Paulista, Bauru, 2010. Disponível em: <https://repositorio.unesp.br/ bitstream $/$ handle $/ 11449 / 102055 /$ monteiro_ma_dr_bauru.pdf? sequence $=1$ \&isAllowed $=y>$. Acesso em: 10 jan. 2019.

MONTEIRO, M. A.; NARDI, R.; BASTOS FILHO, J. B. A sistemática incompreensão da Teoria Quântica e as dificuldades dos professores na introdução da Física Moderna e Contemporânea no ensino médio. Ciência \& Educação, v. 15, n. 3, p. 557-580, 2009. Disponível em: <http://www. scielo.br/pdf/ciedu/v15n3/07.pdf>. Acesso em: 10 jan. 2019.

MOSCOVICI, S. Representações sociais: investigações em psicologia social. Petrópolis: Vozes, 2015.

ORTIZ, A. J.; MAGALHÃES JÚNIOR, C. A. O. Ser professor de Física: Representações Sociais de Licenciandos no primeiro ano de curso. In: TRIANI, F. et al. (org.). Representações Sociais e Educação: contextos e perspectivas. Rio de janeiro: Autografia, 2017. p.181-209.

PARDAL, L. et al. Teaching: what is constant and what is not consolidated in the social representation. Procedia- Social and Behavorial Sciences, v. 159, p. 25-31, 2014.

ROSA, C. W. da; ROSA, A. B. da. O ensino de ciências (Física) no Brasil: da história às novas orientações educacionais. Revista Iberoamericana de Educación / Revista Ibero-americana de Educação, v. 58, n. 2, p. 1-24, 2012. Disponível em: <file:///C:/Users/usuario/Downloads/4689Werner.pdf>. Acesso em: 10 jan. 2019. 
SÁ, C. P. A Representação social da economia brasileira antes e depois do Plano Real. In: MOREIRA, A. S. P.; OLIVEIRA, D. C. (org.). Estudos interdisciplinares de representação social. $2^{\mathrm{a}}$ ed. Goiânia: AB, 2000. p. 49-69.

SALAZAR, S. F. El conocimiento pedagógico del contenido como categoría de estudio de la formación docente. Revista Electrónica Actualidades Investigativas en Educación, v. 5,n. 2, p.118, 2005. disponiovel em: <https://revistas.ucr.ac.cr/index.php/aie/article/view/9139/17507>. Acesso em: 10 jan. 2019.

SAVIANI, D. Formação de professores: aspectos históricos e teóricos do problema no contexto brasileiro. Revista Brasileira de Educação, v.14, n. 40, p. 143-155, 2009. Disponível em: < http:// www.scielo.br/pdf/rbedu/v14n40/v14n40a12.pdf>. Acesso em: 10 jan. 2019.

SHULMAN, L. Those who understand: knowledge growth in teaching. Educational Researcher, v.15, n. 2, p. 4-14, 1986. Disponível em: <https://journals.sagepub.com/ doi/10.3102/0013189X015002004>. Acesso em: 10 jan. 2019.

SHULMAN, L. Knowledge and teaching: foundations of the new reform. Harvard Educational Review, v. 57, n.1, p. 1-23, 1987. Disponível em: <http://hepgjournals.org/doi/10.17763/ haer.57.1.j463w79r56455411>. Acesso em: 10 jan. 2019.

TASSONI, E. C. M.; LEITE, S. A. S. Afetividade no processo de ensino-aprendizagem: as contribuições da teoria walloniana. Educação, Porto Alegre, v. 36, n. 2, p. 262-271, 2013. disponível em: <file:///C:/Users/usuario/Downloads/9584-54538-2-PB.pdf>. Acesso em: 10 jan. 2019.

\section{NOTAS}

${ }^{1}$ Reforçamos que as definições 'alta frequência', 'baixa frequência' e 'OME' têm como referência a frequência média $(\mathrm{F})$ e a OME média. Nesse sentido, baixo é todo valor inferior às médias, enquanto alto é todo valor superior ou igual às médias.

Submetido em 23/01/2018

Aprovado em 22/01/2019

\section{Contato:}

IFPR - campus Ivaiporã

Rodovia PR466, Gleba Pindaúva, Secção C, Parte 2 - Rural

CEP 86.870-000 - Ivaiporã, PR - Brasil 